\title{
Purchasing from Minority Small Businesses
}

\author{
By Marc J. Dollinger, Cathy A. Enz, and Catherine M. Daily
}

Marc J. Dollinger is an Assistant Professor of Business Administration at the School of Business, Indiana University. He earned his Ph.D. degree from Lehigh University. Dr. Dollinger's research has been primarily in the areas of small business, minority business and entrepreneurship.

Cathy A. Enz is an Associate Professor at Cornell's School of Restaurant and Hotel Administration. She received her Ph.D. degree from Ohio State University. Dr. Enz's primary areas of research are in organizational values and culture.

Catherine M. Daily is a doctoral candidate at Indiana University, School of Business. Her dissertation research is in the area of family-owned businesses, governance structure and performance.

(c) Copyright April 1991, by the National Association of Purchasing Management, Inc.
This article employs a transaction costs framework to analyze the problems of Minority Business Enterprise (MBE) purchasing programs. The results from field surveys of small minority firms and corporate purchasing personnel indicate that program participants face differences in transaction costs and in their preferences of ways to overcome these costs. In the majority of situations, minority firms face higher transaction costs than do their corporate purchasing counterparts. The article offers recommendations for improving the performance of MBE purchasing programs, and the policy implications for these programs are discussed.

Many corporations in the United States today have established specific purchasing strategies to attract small business firms owned by Blacks, Hispanics, Asian-Americans, and Native Americans as suppliers. These strategies, known as Minority Business Enterprise (MBE) programs, are implemented by corporations as part of their ongoing practice of developing new suppliers. The programs also encourage the development of a strong and independent minority business sector, while demonstrating the corporation's sense of social responsibility. Likewise, they respond to increasing demands from community groups and the government to stimulate minority-owned small business entrepreneurship. ${ }^{\prime}$

Unfortunately, many of these MBE programs simply do not work as originally planned. Despite the good intentions

The study was conducted in conjunction with the National Association of Purchasing Management (NAPM) and its Center for Advanced Purchasing Studies (CAPS) in 1988, with financial support provided by Arco, Eli Lilly, Northern Telecom, RJR/Nabisco, and US West. The authors wish to thank Mimi Dollinger for her editorial assistance. 
of the corporate sector, minority suppliers perceive and experience barriers that hamper opportunities to increase sales to the corporate community. Corporate purchasing personnel (CPP) recognize these barriers, but do not seem to treat them as seriously as the minority suppliers regard them. At the same time, corporations are frustrated by their failure to achieve MBE purchasing goals and, in some cases, to comply with legal requirements for government contracts.

This article reports the results of a study conducted among corporate buyers and minority suppliers. It identifies some of the causes for this buyer-supplier stalemate, and suggests some solutions. The study also identifies activities favored by both corporate buyers and minority suppliers to reduce or overcome the transaction costs-and it establishes the fact that the suppliers support these activities more than their corporate purchasing counterparts. Finally, the study shows that within the corporation there appear to be different levels of support for transaction cost reducing activities. Corporate buyers and purchasing directors, the on-line personnel responsible for implementing these programs, are less enthusiastic about them than are their managers and upper-level executives. This appears to be a crucial problem for existing MBE programs.

\section{THE STUDY}

The study examined corporate buyer-minority supplier barriers from the perspective of transaction cost economic (TCE) theory. ${ }^{2}$ This theory stipulates that the interactions between economic units can be analyzed by examining the nature and outcome of their economic transactions, and the costs of executing these transactions. It is important to point out that the "costs" of these transactions are not exclusively financial. Costs can be anything that places a toll on the time, enthusiasm, and energy for economic transactions.

Applied to this scenario, TCE theory suggests that if the corporate buyer-minority supplier transactions are difficult to promote or execute, it is because the costs of these transactions are perceived as high by either the minority supplier, the corporation, or both. Faced with high transaction costs, otherwise willing buyers and sellers will be unable to contract, resulting in a form of market failure.

Dàta were collected on a national basis, and included written surveys from 169 minority suppliers (response rate $35.6 \%$ ) and 746 corporate purchasing personnel, including buyers, purchasing managers, and purchasing staff professionals (corporate response rate $27.7 \%$ ). In-depth personal interviews with personnel from 10 minority supplier firms and 13 corporate purchasing staffs were also conducted. The responses represented a good geographical dispersion as well as a wide range of industries. MBE respondents came from 112 different 3-digit zip codes and 83 different 4 digit Standard Industrial Classification (SIC) codes, while corporate respondents represented 102 separate 3-digit zip codes and 21 different 4-digit SIC codes.

Respondents in the minority supplier survey were $\mathbf{4 4 . 4}$ percent Black, 26.6 percent Hispanic, 18.3 percent AsianAmerican, 4.1 percent Native American, 5.3 percent Caucasian, and 1.2 percent from other groups. In contrast, the corporate respondents were 85.7 percent Caucasian and 7.1 percent Black, with the balance made up of small samples from other racial groups.

\section{TRANSACTION COST IMPEDIMENTS}

The transaction cost impediments that both corporate buyers and minority suppliers found to be significant in this study are listed in rank order in Figure 1. The figure displays the perceived importance of these costs as seen by the entire survey group.

Figure 1

\section{RANK ORDER OF IMPORTANCE OF COST IMPEDIMENT SCALES \\ (on a scale of 1 to 7 )}

\begin{tabular}{|c|c|c|}
\hline Rank & Variable & Mean \\
\hline 1 & Atmosphere & $\mathbb{W} \mathbb{W} \mathbb{W} \mathbb{W} \mathbb{W} 4.95$ \\
\hline 2 & Opportunism & $\mathbb{W} \mathbb{W} \mathbb{W} \mathbb{W} 4.30$ \\
\hline 3 & Small Numbers & $\mathbb{W} \mathbb{W} \mathbb{W} \mathbb{W} 4.28$ \\
\hline 4 & $\begin{array}{l}\text { Information } \\
\text { Assymetry }\end{array}$ & $\mathbb{W} \mathbb{W} \mathbb{W} \mathbb{W} 3.99$ \\
\hline 5 & Complexity & $\mathbb{W} \mathbb{W} \mathbb{W} \mathbb{W}^{3.88}$ \\
\hline 6 & $\begin{array}{l}\text { Business } \\
\text { Uncertainty }\end{array}$ & $\mathbb{W} \mathbb{Z}$ \\
\hline 7 & $\begin{array}{l}\text { Production } \\
\text { Uncertainty }\end{array}$ & $\mathbb{W} \mathbb{W} \mathbb{W} \mathbb{W} 3.84$ \\
\hline Where & \multicolumn{2}{|c|}{$\begin{array}{l}1 \text { = Strongly disagree that this is a problem } \\
4=\text { Neither agree nor disagree } \\
7 \text { = Strongly agree that this is a problem }\end{array}$} \\
\hline
\end{tabular}

A response between 4 and 5 represented slight agreement, whereas a response between 3 and 4 indicated slight disagreement. Therefore, the three transaction costs-Atmosphere, Opportunism, and Small Numbers-were the most troubling impediments identified by the combined buyer and seller groups. Other transaction costs judged to be important, although not as significant as these three, are those that stem from Information Asymmetry, Organizational Complexity, Business Uncertainty, and Production Uncertainty. The seven cost factors are discussed in the following paragraphs.

The costs of a negative Atmosphere: the personal costs of doing business that sometimes occur in what can be a hostile, unfriendly, or discriminatory environment. Many minority suppliers responding to the study reported that at times they felt they were being patronized or not taken seriously. Some said that they felt socially ostracized because of their race during the buyer-seller interaction. 
The costs of Opportunism: the costs associated with opportunistic, unethical, or illegal behavior in a purchasing transaction. Like many small businesses that are anxious to compete, the MBE supplier may intentionally, or unintentionally, misrepresent its capabilities in order to win a corporate contract. And, on the other side, corporate purchasing people sometimes encourage minority suppliers to expend significant time and energy qualifying and bidding, even though their prospects for winning a contract are slim, at best. These situations can occur simply because"going through the motions" looks good on the buyer's performance review.

The costs of Small Numbers: the costs of attempting to contract for goods and services in a market with a small number of sellers. The simple fact that there are not a lot of minority suppliers actually hurts the MBE supplier. This is especially true in manufacturing and high technology businesses. Corporate buyers do not always feel confident that there are enough minority suppliers, or that minority suppliers that do exist are qualified enough, to allow them to depend on a reliable flow of purchased materials. Minority suppliers report that often they are unable to buy from each other due to a shortage of reliable suppliers within the MBE community. It appears that minority suppliers frequently do not have the networks and connections they need to act as references for one another.

The costs of Information Asymmetry: the costs of obtaining information that one side to a negotiation has available but the other side does not. Some MBE suppliers complain that they do not receive requests or bid specifications soon enough, or do not receive them as early as other firms do, and that they are not always given enough time to respond.

The costs of Bounded Rationality and Complexity: the costs of dealing with complex rules, large bureaucracies, and inconsistent procedures. Like many small businesses, minority suppliers sometimes have trouble peeling through the corporate red tape and deciphering who is really in charge in the corporation or who they can ask for help or information. This can be a lot of work for the average supplier, especially since it has to work through this maze for every corporation it wants to sell to. Many MBE suppliers complain that the corporate procedure used to certify that they are indeed minority businesses is often onerous and excessively time consuming.

The costs of Business Uncertainty: the costs of maintaining a firm's prospects for performance and survival. Many minority suppliers are plagued by all the traditional problems of small businesses, including inexperienced management, undercapitalization, and strong competition from larger firms. In addition, MBE suppliers complain that they are forced to spend more time getting certified as an MBE supplier than they spend running their business. One supplier reported that winning a large corporate contract almost put his firm out of business; his firm had to borrow a large amount of money to add capacity to fulfill the corporate contract, and then the corporation did not pay promptly enough to permit his firm to repay the loan on schedule.

The costs of Production Uncertainty: the costs of achieving, maintaining, and ensuring high quality output. Again, like many small businesses, MBE suppliers do not always have a refined and reliable quality control system. They often face a special dilemma if they are recruited to produce a product that is either new or different to them, and therefore run the risk of greater variation and subsequent rejection during the production process.

The differential impact of these barriers can be explored more thoroughly by viewing the positions of the corporate purchasing personnel (CPP) and MBE respondents separately. These data are shown in Figure 2 -and reveal a significant variation of the extent to which these transaction costs are perceived to be an impediment.

\section{Figure 2}

\section{COMPARISON OF MBE AND CPP RESPONSES TO IMPEDIMENTS}

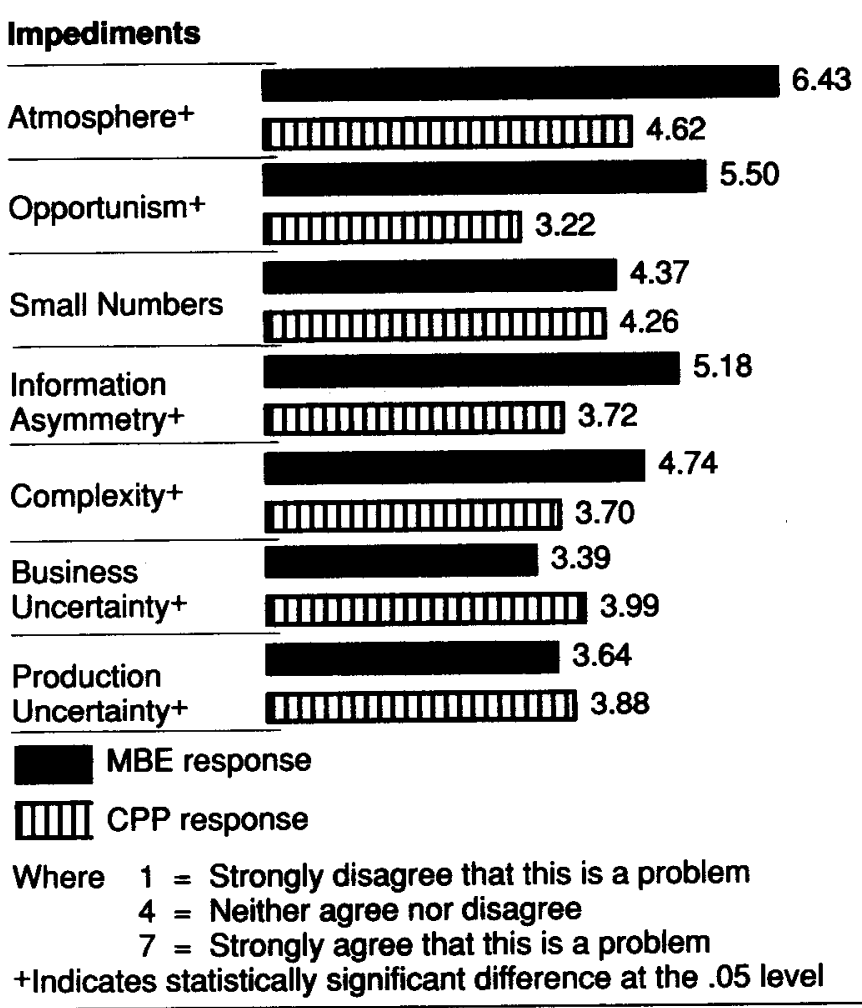

The difference between the CPP and MBE responses is statistically significant for all transaction cost impediments except Small Numbers, which ranked third in importance. A wide difference was found on the two transaction costs ranked most important-Atmosphere and Opportunism. With respect to the atmosphere issue, although there was a large gap between MBEs and CPPs, the CPPs did recognize the importance of the problem and rated it well above 4.00 . However, for opportunism, the CPPs disagreed overall that this was a problem-the average score was 3.22 , well below 4.00. Similarly, the MBEs scored complexity and information asymmetry well above 4.00 , while the CPPs did not recognize these to be problems and rated them under 4.00. And, 
although there was a statistically significant difference between the two groups for the transaction costs of business and production uncertainty, both groups placed less emphasis on these elements, and the average scores fell below 4.00. To summarize, only two of the seven impediments were salient for the corporate purchasing personnel, but five of the seven represented real financial and personal costs for the minority suppliers.

According to transaction cost economic theory, under conditions where the transaction costs of the marketplace are high for both the corporate buyer and the minority supplier, both parties should select some form of internal administration that tends to minimize the costs. In other words, the buyer and the seller go through some sort of merger or integration, or the larger firm simply absorbs the smaller firm. This alternative to the existing market is termed "internalization" in the language of the theory.

However, that option is not feasible in this case. In order to meet social objectives and federal guidelines, the corporate buyer and the minority supplier must exist as separate and distinct entities, and MBE suppliers must flourish independently. This is the paradox of MBE purchasing programs.

\section{COST REDUCING ACTIVITIES}

Activities that can reduce the buyer-seller transaction costs take on increased importance when internalization is not an attractive course of action. Figure 3 outlines the top nine cost reduction activities as ranked by the combined groups of buyers and sellers in the study.

\section{Figure 3}

\section{RANK ORDER OF COMPOSITE ACTIVITY SCALES} (on a scale of 1 to 7 )

\begin{tabular}{|c|c|c|}
\hline Rank & Variable & Mean \\
\hline 1 & Monitoring MBEs & (3\%\% \\
\hline 2 & $\begin{array}{l}\text { Searching for } \\
\text { CPPs }\end{array}$ & 8.39 \\
\hline 3 & $\begin{array}{l}\text { Managerial } \\
\text { Assistance }\end{array}$ & 5.36 \\
\hline 4 & $\begin{array}{l}\text { Searching for } \\
\text { MBEs }\end{array}$ & 奴 5.25 \\
\hline 5 & $\begin{array}{l}\text { Cultural } \\
\text { Interaction }\end{array}$ & \%\$\%\$\%\$ 5.19 \\
\hline 6 & $\begin{array}{l}\text { Monitoring of } \\
\text { CPPs }\end{array}$ & 5.15 \\
\hline 7 & Internalization & $\beta_{14} \alpha^{4} 35$ \\
\hline 8 & $\begin{array}{l}\text { Technical } \\
\text { Assistance }\end{array}$ & $8 \% \beta \% 4.30$ \\
\hline 9 & $\begin{array}{l}\text { Financial } \\
\text { Assistance }\end{array}$ & \$3\%\%3 3.46 \\
\hline
\end{tabular}

The top six variables listed were ranked between 5 and 6 on a 7-point scale, indicating moderate agreement among survey group members. These top variables include the following items.

Monitoring of MBEs: activities that help the corporate buyer keep in close step with the minority supplier. These activities could include training buyers to be sensitive to MBE problems, sponsoring quality control meetings, and such things as requiring performance bonds and checking references and credit. These monitoring activities can reduce business and performance uncertainty as well as the threat of opportunism.

Searching for CPPS: activities that help to make the right match between a supplier and corporate purchasing personnel. Examples of this include a corporation's publishing general information about its purchasing procedures, disseminating a list of current and long-term purchasing needs, and taking a lead role in encouraging minority economic development. These activities act directly against the barriers of small numbers and information asymmetry.

Managerial Assistance: activities that help the supplier make a bid and complete a contract. This can include the use of a qualification process coupled with a process that provides feedback after bidding activities are completed. Sponsoring MBEs at business education programs or providing direct managerial assistance to a supplier can also help achieve this objective. These activities tend to reduce complexity and improve performance reliability.

Searching for MBEs: the flip side of the most favored activity, monitoring of MBEs. This includes corporate promotion through MBE trade fairs and the minority press, distributing an MBE list to each department or purchasing division, and developing national agreements with minority groups. Again, these searching activities combat the costs of small numbers and information asymmetry.

Cultural Interaction: activities that remove or reduce racial bias and therefore improve the atmosphere in which negotiations take place. Training corporate buyers to be aware of minority supplier problems certainly helps, as does corporation employment of minorities as buyers.

One of the most successful corporate buyer-minority supplier relationships that people repeatedly reported during the study's interviews were situations where a former minority employee left the corporation and went into business for himself. This kind of relationship reduces transaction costs in several ways: as a former employee, this supplier is well aware of how his former corporation operates, and because the corporation has experience with the individual, many anxieties are reduced.

Monitoring of CPPS: activities that permit the corporation's purchasing department to check its own progress. These activities include implementing program audits, setting specific purchasing targets, offering incentives to buyers for achieving those targets, and getting top management involved in the MBE process. Again, monitoring activities work against uncertainty and the threat of opportunism.

Internalization: activities that make the exchange between the CPP and MBE easier. While it may not be feasible to merge the two firms, corporate buyers and minority suppliers 
can engage in joint ventures. Corporations can also offer MBEs access to their technical resources and to their internal training capabilities, and they can make investments in venture capital pools for minority suppliers. These kinds of bridging activities tend to lower all the transaction costs.

The two remaining activities are Technical Assistance, which could include corporate assistance with bid preparation and access to technical and management resources, and Financial Assistance, which might include corporate loans, subsidies, guarantees, and the establishment of prepay agreements.

Again, by separating the MBE and the CPP responses, some significant variations in the enthusiasm generated for these activities clearly can be seen. These data are shown in Figure 4.

\section{Figure 4}

\section{COMPARISON OF MBE AND CPP RESPONSES TO ACTIVITIES}

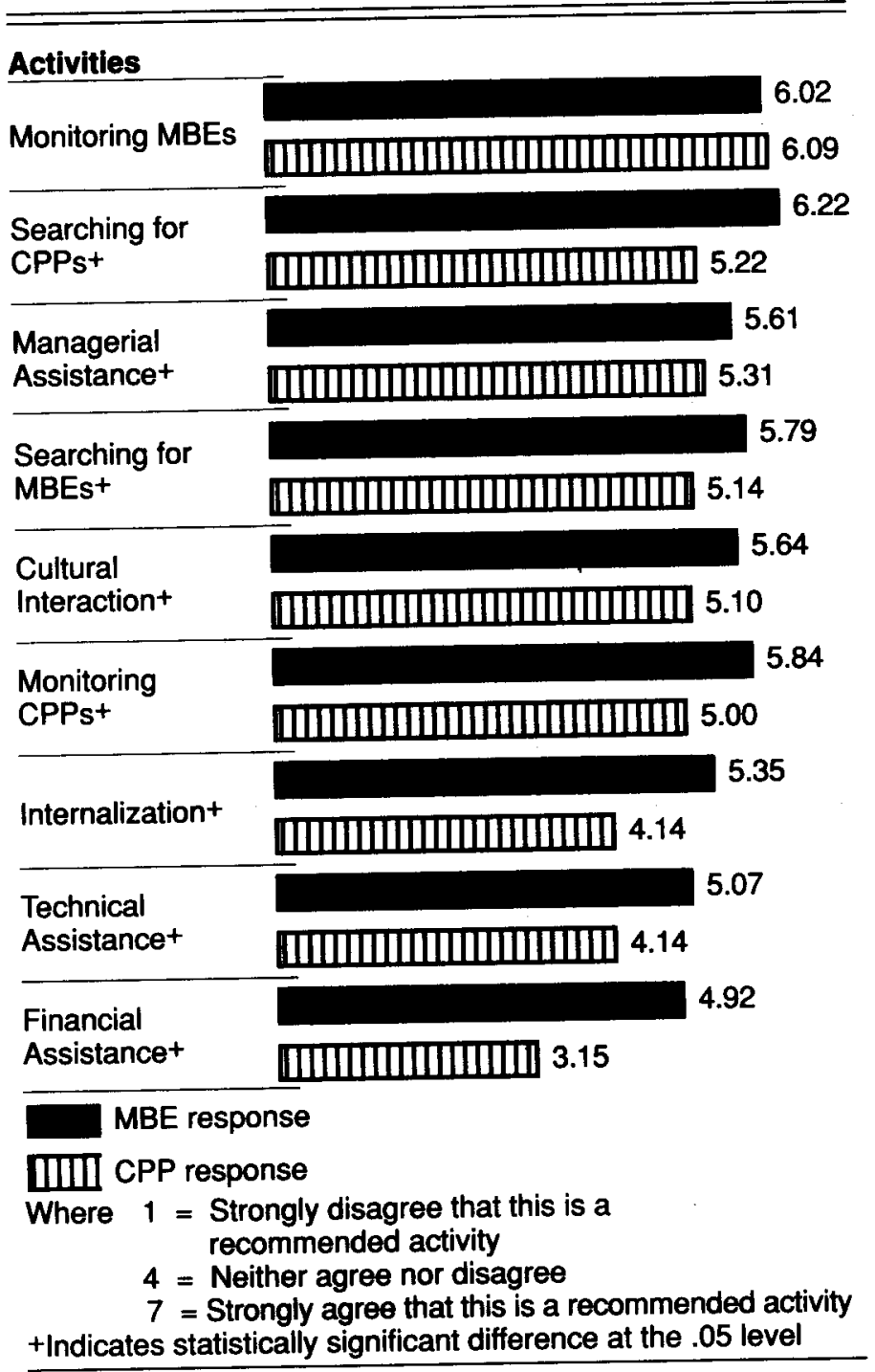

With the exception of Monitoring MBEs, where strong agreement exists between the two groups, the minority suppliers are more anxious to pursue all these cost reducing activities than are their corporate counterparts. The variation in how the activities were ranked is statistically significant for the eight remaining activities and extremely significant for three of those activities in particular-Searching for CPPs, Internalization, and Financial Assistance. This kind of variation may indicate that there simply are not enough of these types of activities currently being offered or that such activities that are available are not working effectively.

Minority suppliers that seek to increase sales through the use of longer term contracts with large corporations have much to gain from these activities, and that undoubtedly accounts for some of their enthusiasm. And the costs for most of these activities-the sharing of resources, promotion and publicity, education, and financial aid-are born by the corporation, not by the minority supplier. Still, the difference in the levels of support between purchasers and suppliers for these programs may suggest why current MBE programs do not always work.

Variation in the support for these activities occurred among corporate personnel, too. In the study, corporate personnel were asked to classify themselves under one of four job titles: buyer, manager, corporate staff, and corporate executive. Analysis of CPP responses by job title showed that the lower an individual stood on the corporate ladder, the less likely he or she was to endorse impediment reducing activities.

There was statistically significant variation among job titles for all activities except Financial Assistance, and marked deviation for all the searching and monitoring activities. This may reflect the fact that individuals low on the corporate ladder, namely buyers and some managers, bear the responsibility and therefore the costs of implementing these activities. At the same time, senior management, whose only involvement may be in the planning activity, is more likely to get the credit when a program works well. These varying levels of enthusiasm within the corporation may again indicate why current MBE programs do not always work, and suggest that the key to making them work is to find ways to generate enthusiasm and acceptance among the people charged with "hands on" implementation.

\section{RECOMMENDATIONS}

Analysis of the responses from this study suggests several plans of action for individuals interested in making MBE programs successful, especially for representatives from the corporate community.

The first recommendation is to work harder at the programs that are already in place. The research indicates that both corporate purchasing personnel and minority suppliers are aware of the kinds of activities that could improve their relationships but simply are not implementing them. This is where the framework of the theory of transaction cost economics is helpful, because it allows the analyst to look at potential purchasing agreements in terms of impediments, 
or transaction costs, that hamper them-and it permits the organization to focus on those activities that reduce the transaction costs between CPP and MBE. As discussed earlier, this means (1) reducing the complexity, (2) increasing the pool of qualified MBEs, (3) improving the atmosphere for negotiations, (4) encouraging trust while discouraging opportunistic behavior, (5) minimizing business uncertainty, and (6) keeping the information lines open in both directions.

A second recommendation is for the buying organization to do as much as is practical to shift transaction costs away from the purchasing personnel responsible for negotiating contracts with minority suppliers. By doing that, they can separate the processes where decisions are made to contract with particular suppliers from the mechanisms used in searching for those suppliers and subsequently qualifying and monitoring them. The research shows that these latter mechanisms are barriers, or have a high cost, for many corporate buyers. Administrative units or personnel, including staff specialists outside of purchasing, specialists within purchasing who have no responsibility for contract negotiation, or even units outside the corporation such as Regional Minority Supplier Development Councils (RMSDCs) can perform some of these searching and monitoring functions. Funded by a system of dues and membership fees, RMSDCs can effectively absorb these transactions and their related costs, and facilitate agreements. They can also provide economies of scale (size) and scope (range of activities) that a single purchasing organization might not be able to do.

The third recommendation concerns the criteria for evaluating the results of MBE purchasing programs. The authors suggest that corporations adopt multiple criteria for evaluating these programs and the performance of their purchasing personnel. Quantitative goals, like total sales dollars and a federal quota, are useful, but limited. Indeed, sometimes they work against the promotion of minority business because a filled quota ceases to be a motivator, and an unattainable dollar figure (in the absence of sanctions) produces cynicism. Qualitative goals and criteria, with flexibility to allow many different modes of success, are recommended to augment current methods.

The final recommendation is to experiment with selected innovative programs, particularly innovations that fall under the heading of "internalization." These programs require the mixing of corporate and MBE resources, assets, money, and people as a replacement for arms-length contracting. Internalization can be a way to bring the MBE and the corporation together, either physically or contractually, for a self-defined period of time. After the firms are separated and once again legally distinct, the benefits remaintransaction costs are permanently reduced.

A few examples can illustrate this recommendation. An MBE incubator facility, which is essentially a sharing device that allows a number of small businesses to share space costs, administrative overhead, and specialized employees, could reduce business uncertainty and production uncertainty. Supported by corporate financial and managerial assistance, the incubator would enable the CPP to directly observe and monitor the progress of the MBEs, and provide the MBEs with immediate access to corporate personnel and information. In this kind of facility, the MBEs would no longer be "outsiders" faced with overcoming all the barriers of selling to a separate corporation.

A more revolutionary suggestion is for the corporation to develop a "repurchasing agreement" for minority-owned businesses. This would entail having a corporation literally buy an MBE for a limited time under a contract in which the minority owner agrees to repurchase the business at a pre-arranged time for a pre-arranged price. During the period of corporate ownership, the minority owner would be paid a salary and would be an employee of the corporation. During this period of operation, many of the transaction cost barriers should be minimized or overcome, with the expectation that the improved working relationship would continue after the repurchase.

A final example of the internalization approach is a program analogous to affirmative action recruitment of college students. In this program, minority students who are interested in pursuing entrepreneurial opportunities would be recruited by the corporation for a special training and employment program. Part of their training would be exposure to corporate operations that are best suited to MBE procurement. When the trainee leaves the corporation, he or she would be uniquely suited to act as a supplier for his or her former employer. While this may appear to be a relatively expensive program, it could be extremely effective in reducing the transaction costs of later procurement.

Sometimes the key to problem solving is not a new solution but a new approach. Transaction cost economic theory and the feedback from this study facilitate a reevaluation of the barriers that hamper the success of current MBE programs - and also provide an opportunity to reduce those barriers or costs by refining existing programs in terms of TCE theory. This framework also suggests two new solutions to break the corporate purchaser-minority supplier stalemate: (1) programs that shift the burden of transaction costs away from the contract makers, and (2) innovative programs that reduce barriers by blending corporations and minority-owned small businesses. Responses to the survey confirm that MBE programs can develop new resources for corporations and simultaneously encourage the development of minority entrepreneurs, if these transaction costs can be recognized as barriers-and then be shifted or reduced.

\section{REFERENCES}

1. T. Bates, "Impact of Preferential Procurement Policies on Minority-Owned Businesses," The Review of Black Political Economy, 14, 1985, pp. 51-65; S. Dowst, "Sure Route to Better Minority Sourcing," Purchasing, October 8, 1981, pp. 77-81; T. Spratlen, "The Impact of Affirmative Action Purchasing," Journal of Purchasing and Materials Management, 14, 1978, pp. 8-11.

2. J. Robins, "Organizational Economics: Notes on the Use of Transaction Cost Theory in the Study of Organizations," Administrative Science Quarterly, 32, 1987, pp. 68-86; O. Williamson, Markets and Hierarchies (New York: Free Press, 1975); O. Williamson, "The Economics of Organization: The Transaction Cost Approach," American Journal of Sociology, 87, 1981, pp. 548-77. 